\title{
Research on China's carbon emission trading market
}

\author{
Yingkai Yin ${ }^{1}$, Lei Zhou ${ }^{2}$ and Yanzhou Chen ${ }^{3}$ \\ 1. 2 School of Economics, Shanghai University, shanghai, China
}

Keywords: Carbon emission trading, China's Pilot ETS, Auto regression model

Abstract: Since EU ETS established in 2005, the international carbon emission trading markets have been running for 12 years, while China's Pilot ETS just for three years. However, owing to the high level carbon emissions, China's carbon emission trading market has a huge development space. The first part compared current situation between the international and domestic carbon emission trading markets, and indicated some outstanding problems in China. Then this paper studied the inherent relationship between weekly trading volume and return rate in Shanghai ETS, based on the Autoregressive model. Results show that the carbon emission trading volume in Shanghai is fluctuating, and the impact of return rate on the current trading volume is more significant. Finally, this paper gave some suggestions to perfect the carbon emission trading market in China: (i) use financial derivatives to active trading market; (ii) make incentive policies to stimulate transactions; (iii) unify carbon emission trading market regulations.

\section{Introduction}

With the Kyoto Protocol, the Copenhagen Accord, the Paris Agreement signed, countries have begun to establish the carbon emission trading systems (ETS), and the trading markets are becoming more mature. According to the trading motive, global markets can be divided into the mandatory emission reduction market represented by the EU ETS and China's Pilot ETS, and voluntary emission reduction market represented by the Chicago ETS. The main participants include organizers, regulatory authorities, intermediary services and market traders (see Fig1).Nowadays the world's major carbon exchanges are spread in Europe, America, Oceania and Asia. Trading products cover spot, options, futures, funds, insurance and bonds.
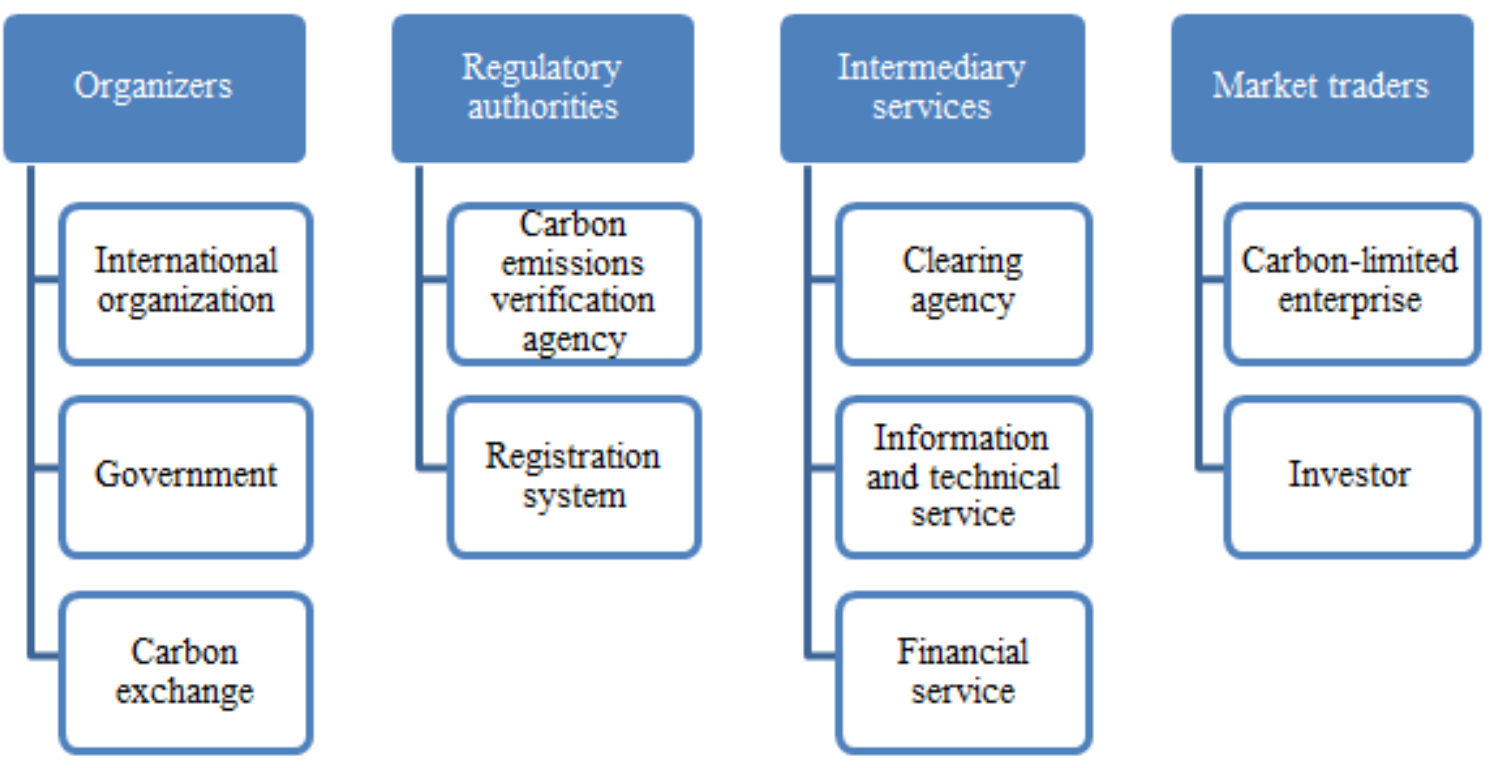

Figure 1 The main participants in global carbon trading market

In November 2015, China government promised at the Global Climate Change Conference that 
China's carbon emissions will reach peak in 2030 and $\mathrm{CO}_{2}$ emissions per unit of GDP will reduce by $60 \%$ to $65 \%$ compared to 2005 . To achieve the target as soon as possible, the establishment of carbon trading emission system is actively promoted. The seven Pilot ETS (Beijing, Guangdong, Shenzhen, Tianjin, Hubei and Shanghai) have begun to take sharp. In December 2016, Chongqing and Fujian also joint. Trading products are based on spot, including carbon emission allocations and Chinese certified emission reductions (CCERs). As of October 20 $0^{\text {th }}, 2017$, the total volume of China's pilots is about 130 million tons and the turnover is 2.7 billion yuan. Among them, the total volume and turnover in Hubei province are highest, accounting for $36.76 \%$ and $33.09 \%$ (see Fig 2).

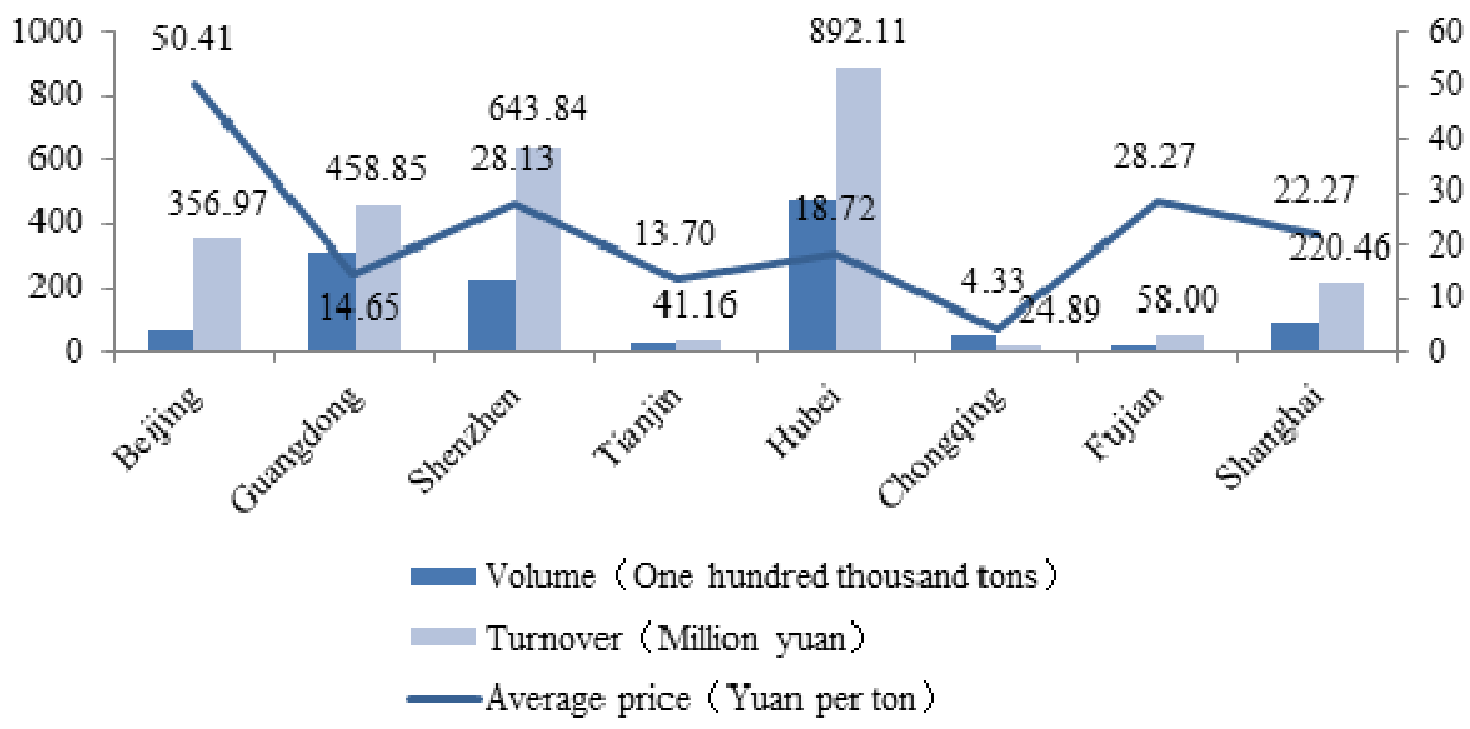

Figure 2 The volume, turnover, average price of China's Pilot ETS

However, there are still some problems to be solved in China's carbon emission trading market:

(i)Single product is not conducive to innovation

Financial derivatives in some mature carbon trading markets, such as EU and Chicago, are growing rapidly. Options and futures which subject matter is carbon emission right have been standardized. But China's pilots are based on carbon spot and lack of product innovation. Futures, options and funds are still in the trial stage. In July, 2017, the first carbon emission option was traded at home. Therefore, China's carbon emission trading market still has a big gap compared with the international markets.

(ii) Market segmentation is not conducive to a unified carbon market

China's Pilot ETS are divided at the beginning, so every pilot has their own trading rules. There are differences in coverage industries, entry threshold, trading subjects, products, regulatory rules and so on. In addition to Beijing and Shenzhen, other pilots built trading rules under the local government management methods, so legal binding force is weak.

(iii) Poor liquidity is not conducive to the construction of carbon price mechanism

Pilots' carbon emission trading is concentrated in the performance period, after that there are few transactions. Every pilot's performance period is in June. Enterprises often accelerate their trading speed in secondary market in order to accompany their tasks, so the volume and turnover continue high in June. For example, in June the total volume and turnover in Shanghai ETS are 1.46 million tons and 5.04 million yuan, but from July to October, they are only 26 thousand tons and 775 thousand yuan. Weak liquidity is not enough to attract financial investment institutions to enter the trading market and enterprises can't predict the change of carbon price. If carbon price rises sharply, it will increase carbon reduction cost; if the price is too low, it will affect the enthusiasm to participate in the trading market. 
First this paper pointed out some problems in the domestic market based on comparisons of current situation of carbon emission trading markets in China to the world. Then AR model was used to analyze the relationship between carbon trading volume and return rate in Shanghai ETS from January $1^{\text {st }}, 2017$ to October $20^{\text {th }}, 2017$. Finally, this paper put forward suggestions to perfect the trading market.

\section{Literature Review}

In recent years, many scholars have been interested in China's carbon emission trading market. Yasheng Zhou et al (2013) found that the CER spot price is positively affected by macroeconomic indicators and climate indicators, and the impact of futures prices is also significant. Ke Ding et al (2015) considered that the amount of CDM is negatively correlated with CER price in secondary market, while electricity price, crude oil price, natural gas price and coal price are positively. Jiarui Shi et al (2015) concluded that carbon trading mechanism can effectively reduce carbon intensity and energy intensity, as well as promote the process of energy saving and emission reduction in China. But it also has a negative impact on economic output. Qingshan Wang et al (2016) proposed that reducing coke price, slowing down the pace of economic development, enhancing market active and increase penalties for breach of contract, are conducive to reducing the price difference between China's Pilot ETS, and then form an effective method to unify carbon price. Xin Chen et al (2016) found that PMI and coal price have a positive impact on carbon price, and oil price and the stock market have a negative impact on carbon prices, while the impact of weather on the carbon price is not significant. Villoria-Saez et al (2017) put forward that a fine of $\$ 90.22$ per ton is the best penalty for achieving maximum carbon reduction. Xueping Tan et al (2017) found that China's Pilot ETS performance is mainly due to the lack of legal binding force, market stagnation, excessive allocation and lack of investment. Xingang Zhao et al (2017) thought that with the increase of trading volume and scale, China's carbon emission market will move from low efficiency to low profitability.

In short, many scholars think that carbon price is an important indicator to reflect the performance of carbon emission trading market. By studying the intrinsic relationship between carbon price and macroeconomic, energy and climate change, they put forward some feasible suggestions to establish and improve carbon pricing mechanism, and then promote to unify trading market. However, few scholars study the influencing factors of trading volume.

\section{Model Analysis}

Actually, the relationship between the explaining variable and the explained variable cannot occur instantaneously. There is usually a "time lag". That is to say, explaining variables need to take a period time to fully function on the explanatory variable. The reasons of lag are mainly from people's psychological factors, technical factors and institutional factors. If a variable can take the value of the past period, it is called a lag variable. A regression model included lag variables is the lagged variable regression model.

The lagged variable regression model's general form is:

$$
Y_{t}=\alpha_{0}+\beta_{0} X_{t}+\beta_{1} X_{t-1}+\beta_{2} X_{t-2}+\ldots+\beta_{s} X_{t-5}+\gamma_{1} Y_{t-1}+\gamma_{2} Y_{t-2}+\ldots+\gamma_{q} Y_{l-q}+\mu_{i}
$$

This paper established the model (2) based on the Autoregressive model: 


$$
T_{i}=\alpha_{0}+\alpha_{1} R_{i}+\beta_{1} T_{i-2}+\beta_{2} T_{i-2}+\varepsilon_{i}
$$

where $T_{t}$ is weekly carbon emission trading volume, $R_{t}$ is return rate, and $\varepsilon_{t}$ is random error term.

This paper elected weekly trading data in Shanghai ETS from January $1^{\text {st }}, 2017$ to October $20^{\text {th }}$, 2017. The Augmented Dickey Fuller (ADF) test and descriptive statistics for all variables in Table 1 exhibit that all the data series are stationary that can be used to examine the internal performance.

Table 1 Descriptive statistics and unit root test

\begin{tabular}{|c|c|c|c|c|c|c|}
\hline Variables & Mean & Median & Maximum & Minimum & Std. Dev. & Result \\
\hline $\mathrm{T}_{\mathrm{t}}$ (ten thousand tons) & 55.76 & 10.42 & 584.45 & 0 & 120.38 & Stationary \\
\hline $\mathrm{R}_{\mathrm{t}}(\%)$ & 0.15 & -0.19 & 21.86 & -13.31 & 5.41 & Stationary \\
\hline
\end{tabular}

By using Eviews, the data regression results are showed in Table 2.

Table 2 Regression results of model (2)

\begin{tabular}{|c|c|c|}
\hline \multicolumn{3}{|c|}{ Dependent Variable: $\mathrm{Tt}$} \\
\hline \multicolumn{3}{|c|}{ Method: Least Squares } \\
\hline \multicolumn{3}{|c|}{ Included observations: 42} \\
\hline Variable & Coefficient & t-Statistic \\
\hline $\mathrm{R}_{\mathrm{t}}$ & 2.04 & 0.793865 \\
\hline $\mathrm{T}_{\mathrm{t}-1}$ & 0.88 & 5.818971 \\
\hline $\mathrm{T}_{\mathrm{t}-2}$ & -0.37 & -2.465893 \\
\hline $\mathrm{C}$ & 26.78 & 1.757258 \\
\hline \multicolumn{2}{|c|}{ R-squared } & 0.51 \\
\hline \multicolumn{2}{|c|}{ F-statistic } & 13.38 \\
\hline \multicolumn{2}{|c|}{ Durbin-Watson stat } & 2.08 \\
\hline
\end{tabular}

Therefore,

$$
T_{t}=26.78+2.04 R_{t}+0.88 T_{t-1}-0.37 T_{t-2}
$$

When $R_{t}$ is equal to zero, the characteristic root equation of the model (3) is

$$
\lambda^{2}=0.88 \lambda-0.37
$$

Obviously,

$$
\Delta=0.88 \times 0.88-4 \times 1 \times 0.37=-0.7056<0
$$

The reasons show us that:

(1)If the significance level is $1 \%, \mathrm{~F}=13.38>\mathrm{F}_{0.01}(3,38)$, that indicates the linear relationship is significant.

(2)D.W. $=2.08 \in\left(\mathrm{d}_{\mathrm{u}}, 4-\mathrm{d}_{\mathrm{u}}\right)$, indicating the model (3) has no first order serial correlation.

(3) $\alpha_{1}=2.04$, indicating when return rate increases $1 \%$, the trading volume increases $2.04 \%$; $\beta_{1}=0.88$, indicating when the trading volume last week increases $1 \%$, the volume this week increases $0.88 \% . \alpha_{1}$ is more than twice than $\beta_{1}$, and the mean and standard deviation(Std. Dev.) of 
the return rate are $0.15 \%$ and $5.41 \%$, indicating that the impact of return rate is much greater on the trading volume.

(4) $\beta_{2}=-0.37, \Delta<0$, which indicate that volatility of the time series $T_{t}$ is significant.

\section{Conclusions}

To improve and unify China's carbon emission trading market, this paper gives the following suggestions:

First, enrich types of products. Various financial products can activate the carbon emission trading market and attract investment institutions to participate. China can learn from other mature carbon emission trading markets, and expand the commodity from carbon dioxide to other greenhouse gases such as methane and $\mathrm{SO}_{2}$.Also China can develop options, futures and other financial derivatives.

Second, establish incentive mechanism. The government can design preferential policies or fiscal incentive measures to stimulate the enthusiasm of enterprises. Then financial institutions will also actively participate in market and carbon trading volume during non- performance period will increase.

At last, unify carbon emission trading regulations. The national ETS will start soon. Only depending on market mechanism is insufficient. The trading regulations at the national level are the prerequisite for harmonizing the carbon emission trading market. Regulations should clarify the targets of carbon reduction, the allocation of carbon emission, the scope of industries, as well as the registration, monitoring, reporting and regulatory agencies.

\section{Acknowledgement}

This research was financially supported by the National Science Foundation (71171128) and National Social Science Foundation (17BJY062).

\section{Reference}

[1] Yasheng Zhou, Wei Wei. Study on the influencing factors of spot price of Certified Emission Reduction. Financial Research, Vol. 10(2013), p.142-153.

[2] Ke Ding, Huanxue Pan and Tao Qin. Empirical study on the factors of international carbon emission price based on supply and demand. Financial Economy, Vol. 22(2015), p. 69-72.

[3] Jiarui Shi, Hailin Cai, Ling Tang and Lean $\mathrm{Yu}$. Research on the impact of carbon trading mechanism on China's economic environment based on CGE model. China Management Science, Vol. 23(2015), p. 801-806.

[4] Paola Villoria-Sáez, Vivian W.Y. Tam, Mercedes del Río Merino, Carmen Viñas Arrebola, Xiangyu Wang. Effectiveness of greenhouse-gas emission trading schemes implementation: a review on legislations. Journal of Cleaner Production, Vol. 127(2016), p. 49-58.

[5] Xueping Tan, Xinyu Wang. The market performance of carbon trading in China: A theoretical framework of structure-conduct-performance. Journal of Cleaner Production, Vol. 159(2017), p. 410-424.

[6] Information on http://www.tanpaifang.com 